\title{
Fuzzy Modeling Approach to On-Hand Stock Levels Estimation in $(R, S)$ Inventory Systems with Lost Sales
}

\author{
Ester Guijarro ${ }^{1}$ (D) Eugenia Babiloni' ${ }^{1}$ D, Maria Jose Canós-Darós² (iD, \\ Lourdes Canós-Darós $^{1}$ (iD, Sofía Estellés-Miguel ${ }^{1}$ iD \\ ${ }^{1}$ Universitat Politècnica de València (Spain) \\ ${ }^{2}$ Universitat de València (Spain) \\ esguitar@doe.upv.es,mabagri@doe.upv.es,Maria.J.Canos@uv.es,loucada@omp.upv.es,soesmi@doe.upv.es
}

Received: December 2019

Accepted: May 2020

\begin{abstract}
:
Purpose: One challenge in inventory control models is to know the stock available at the beginning of the cycle to satisfy future demands, i.e. to know the on-hand stock levels at order delivery. For inventory managers, this knowledge is necessary to both determine service levels and establish the control parameters of the inventory policy. However, the calculation of on-hand stock levels when unfilled demand is lost is mathematically complex since on-hand stock cannot be negative by definition. The purpose of this paper is to propose a new approach to estimate on-hand stock levels when the inventory is periodically reviewed and unfilled demand is lost, through the use of fuzzy techniques.
\end{abstract}

Design/methodology/approach: This paper applies fuzzy set techniques for the calculation of the on-hand stock levels at order delivery in the lost sales context, based on the uncertainty that real demand introduces. To this end, we propose a new approach based on modeling the on-hand stock as an imprecise Markov chain using possibility functions, which reduces significantly the computational effort required to obtain the on-hand stock levels.

Findings: To illustrate the performance of the proposed method, two experiments are carried out. The first experiment shows that the proposed fuzzy method correctly calculates on-hand stock levels with insignificant deviation with respect the exact vector. Additionally, the results illustrate that the fuzzy method simplifies the calculation and highly reduces the computational efforts. The second experiment shows the performance of the fuzzy method when it is used to estimate service levels by means of the fill rate. The results show that the proposed method accurately estimates the fill rate with average deviations lower than 0.00015 .

Practical implications: Knowing the on-hand stock vector is important for inventory managers to establish the control parameters of the system, i.e. to determine the minimum base stock level, $S$, that guarantees the achievement of a target service level. The difficulty of this estimation is that to obtain the on-hand stock vector in a lost sales context requires a huge computational effort and it is difficult to implement in companies' information systems. However, the proposed fuzzy method leads to a very accurate calculation of the on-hand stock vector significantly reducing the computational costs, which makes this method easily implementable in practical environments.

Originality/value: Fuzzy set techniques have been widely used in inventory models to introduce the uncertainty of demand, costs or shortage. However, to the best of our knowledge, this is the first paper which deals directly with fuzzy estimation of on-hand levels.

Keywords: inventory, on-hand stock, fuzzy set, lost sales, periodic review 


\section{To cite this article:}

Guijarro, E., Babiloni, E., Canós-Darós, M.J., Canós-Darós, L., \& Estellés-Miguel, S. (2020). Fuzzy modeling approach to on-hand stock levels estimation in $(R, S)$ inventory systems with lost sales. Journal of Industrial Engineering and Management, 13(3), 464-474. https://doi.org/10.3926/jiem.3071

\section{Introduction}

Inventory management is probably one of the most highly developed disciplines within operations management due to its strategic importance for companies (Chikán, 2007). The success of any organization depends on its ability to have enough units to satisfy all the demand whilst simultaneously minimizing costs (Chikán, 2011). For that reason, knowing the available on-hand stock levels, i.e. stocks that are on shelves ready to be used, becomes a challenge and one of the most important issues to determine both customer service levels and the costs of the inventory system. This paper focuses precisely on the estimation of the on-hand stock levels at the beginning of the replenishment cycle, i.e. just after a replenishment order delivery when the inventory is periodically reviewed according to the traditional base-stock policy.

The first challenge related to the determination of stocks levels consists in establishing the stock balance at order delivery for which it is necessary to set the control procedure the company uses when a stockout occasion occurs. Basically, there are two extreme procedures: backordering unfulfilled demand and fulfilling it as soon as the replenishment order arrives, or losing the entire unfilled demand. Traditionally, inventory research has focused on the first case (i.e. backordering unfilled demand), mainly because backordering models are easier to formulate and analyze than lost sales models (Bijvank, Huh, Janakiraman \& Kang, 2014; Johansen, 2013; Kouki, Babai, Jemai \& Minner, 2018). However, many sectors have to manage their inventories taking into account that if customers do not find the product, they will go to other sources to satisfy their needs. For example, in sectors such as retail (Gruen, Corsten \& Bharadwaj, 2002), service (Diels \& Wiebach, 2011) or e-commerce (Breugelmans, Campo \& Gijsbrechts, 2006). For all these cases, inventory managers require appropriate expressions to characterize inventory policies despite the mathematical complexity that the lost sales context entails.

The problem of the determination of stock levels for the lost sales context has been addressed in (Cardós \& Babiloni, 2011a,b) where the mathematical complexity and the computational effort required for the computation of the vector that represents the probability of every feasible value is explained in detail. However, managers are expecting methods that improve managerial insight and are, at the same time, implementable in practice, as is highlighted in Silver (2008).

The objective of this paper is precisely to provide an accurate and implementable method to estimate the probability of the on-hand stock vector at the beginning of the cycle when the inventory is periodically reviewed and unfilled demand is lost. To fulfill our objective, we develop a new method that applies fuzzy set techniques (Zadeh, 1965) based on the uncertainty that real demand introduces to any inventory problem. Note that this research introduces fuzzy set theory for the first time in the estimation of stock levels. We demonstrate that our method is accurate enough and significantly reduces mathematical and computational efforts, which represents a significant benefit from a practical perspective.

The last decades, fuzzy set theory has been widely applied in the areas of production and operations management (Guiffrida \& Nagi, 1998; Kahraman, Gülbay \& Kabak, 2006; Ko, Tiwari \& Mehnen, 2010; Mula, Poler, García-Sabater \& Lario, 2006), including inventory management. Characterizing inventory systems is often difficult mainly due to the uncertainty involved in the system. In the literature, different fuzzy inventory models have been proposed such as fuzzy EOQ (economic order quantity) and EPQ (economic production quantity) models, fuzzy supply chain models, fuzzy newsvendor models or fuzzy inventory control models (such as this paper). See Shekarian, Kazemi, Abdul-Rashid and Olugu (2017) for a deep review and categorization of fuzzy inventory models. Some models incorporate fuzzy techniques to model the uncertainty of demand (Dey \& Chakraborty, 2012; Dutta, Chakraborty \& Roy, 2007; Garg, 2015; Sarkar \& Mahapatra, 2015). Other models uses it to determine 
the costs of the inventory systems (Dey \& Chakraborty, 2011; Katagiri \& Ishii, 2002; Pai \& Hsu, 2003; Taleizadeh, Niaki \& Aryanezhad, 2010) or introduce fuzzy numbers to handle the uncertain information in the data (Garai \& Garg, 2019). Thus, application of fuzzy techniques facilitates dealing with real practical situations in a more proper way. However, as a novel approach, our research introduces a new perspective of the application of fuzzy techniques on inventory models; its application on the estimation of stocks levels.

The rest of the paper is organized as follows. Section 2 presents the difficulty of the on-hand stock levels calculation when lost sales are assumed. In Section 3, we propose a new fuzzy approximation and some numerical examples are presented to illustrate the computational reduction cost of the proposed method. Section 4 shows the impact of the fuzzy on-hand stock levels when are used to calculate service measures. Finally, Section 5 highlights the most relevant conclusions of this work and presents further studies.

\section{On-Hand Stock Levels in Periodic Review $(R, S)$ Systems with Lost Sales}

In this paper, we focus on the calculation of the on-hand stock levels in a single echelon single item inventory system, which is periodically reviewed. Figure 1 shows an example of typical behavior of this type of system. The periodic review, base stock $(R, S)$ system, also known as a replenishment cycle system, places a replenishment order every $R$ units of time (i.e. at each review instant, $R-L$ ) to raise the inventory position to the base stock level $S$. The replenishment order arrives after a lead time, $L$, and these products are available for the next period. Both, the lead time, $L$, and the review period, $R$, are known. The demand that arrives at the system during a period is fulfilled with the on-hand stock at the beginning of that period, therefore unfilled demand is lost. It is assumed that only one outstanding order is launched within any period, which means that $L<R$. Notation used in the paper is:

$S \quad=$ base stock (units),

$\mathrm{R} \quad=$ review period and replenishment cycle corresponding to the time between two consecutive deliveries (time units),

$L \quad=$ lead time for the replenishment order (time units),

$\mathrm{OH}_{t}=$ on-hand stock at time $t$ (units),

$I P_{t} \quad=$ inventory position at time $t$ (units),

$N S_{t} \quad=$ net stock at time $t$ (units),

$D_{t} \quad=$ accumulated demand during $t$ consecutive periods (units),

$f_{t}(\cdot) \quad=$ probability mass function of $D_{t}$,

$F_{t}(\cdot)=$ cumulative distribution function of $D_{t}$,

$X^{+}=\operatorname{maximum}\{X, 0\}$ for any expression $X$,

$E[X]=$ expected value of expression $X$.

As the introduction points out, an important piece of information for inventory managers is to know the on-hand stock levels at order delivery, i.e. $\overline{P\left(\mathrm{OH}_{R}\right)}$, since it is required to compute service measures or to design optimal inventory policies. However, the calculation of $\overline{P\left(\mathrm{OH}_{R}\right)}$ is quite complex under the lost sales assumption when compared to the backordering case. Inventory models use the inventory position as an indicator of the inventory status. In backordering models the inventory position is computed as the net stock plus stock on order. The net stock is the on-hand stock minus any backorders, so that negative net stocks represent stockouts. Therefore, the on-hand stock level at order delivery can be straightforwardly calculated as the difference between the inventory position at the review instant $\left(I P_{R-L}=S\right)$ and the accumulated demand during the lead time $\left(D_{L}\right)$, i.e. $O H_{R}=S-D_{L}$. In contrast, in lost sales models the inventory position is computed by means of the on-hand stock which is the same as positive net stocks, thus the inventory position does not decrease when a stockout takes place (Bijvank \& Vis, 2011). In this case, since the on-hand stock cannot be negative by definition, the on-hand stock level at order delivery is computed as $O H_{R}=\left[S-D_{L}\right]^{+}$. 


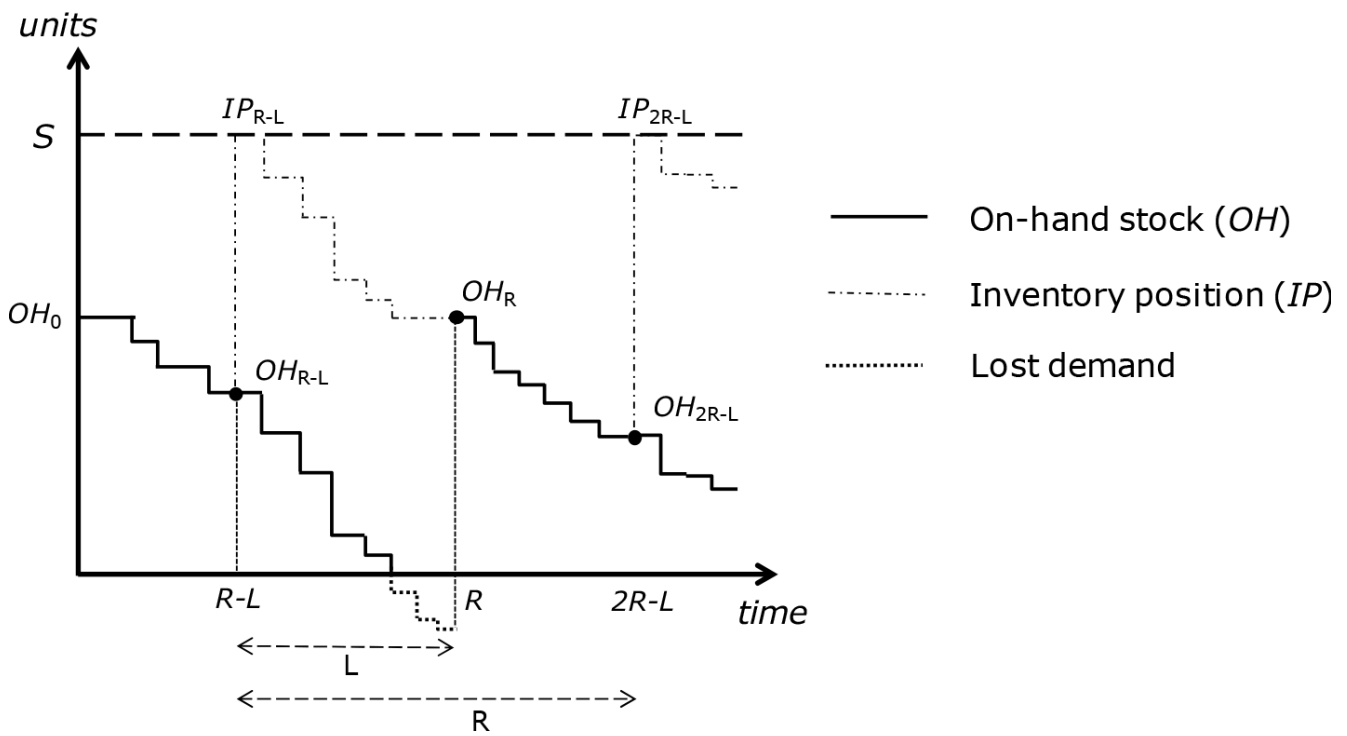

Figure 1. On-hand stock and inventory position evolution in a periodic review $(R, S)$ system with lost sales

Cardós, Miralles and Ros (2006) propose an exact method to compute the on-hand stock level in a periodic review and lost sales system by modelling the on-hand stock evolution as an ergodic regular Markov Chain where the eigenvector of the transition matrixes between states represents the probability of every possible on-hand stock level at order delivery. The difficulty of this expression is that it requires a huge computational effort (especially for high levels of $S$ ) which also hinders its implementation in practical environments. In the literature we find other works (Babiloni, Cardós \& Guijarro-Tarradellas, 2011; Bijvank \& Johansen, 2012; Cardós, Guijarro \& Babiloni, 2017) that propose different approximations to calculate the on-hand stock levels in the lost sales context, however, none of them introduces the uncertainty of the demand in the model. To overcome these drawbacks, this paper proposes the application of fuzzy set techniques on the on-hand stock estimation that introduce the uncertainty of the demand and dramatically reduce computational efforts.

\section{Fuzzification of the On-Hand Stock Levels}

To accurately compute the probability vector of the on-hand stock levels, Cardós et al. (2006) propose an inductive approach based on modeling the inventory system as a regular Markov Chain. This method computes the probability transition matrices of the on-hand stock levels from the beginning of each cycle to its end. The convergence of these matrices leads to the attainment of the principal eigenvector, which represents the on-hand probability vector at order delivery. However, as Cardós and Babiloni (2011a) point out this approach "is not appropriate to be widely used in a business context" because it requires "a sound of mathematical background" and the convergence of matrixes "eventually may also be time consuming" especially for large base stock levels.

To overcome these drawbacks, we propose a new fuzzy approach based on modeling the evolution of the on-hand stock over the replenishment cycle as an imprecise Markov chain using possibility functions. This new approach allows the simplification of the calculations since the convergence of matrixes are not required. This fact significantly reduces the computational effort to obtain the on-hand vector.

The procedure is as follows. Firstly, we define $\overline{\overline{M_{R}}}$ as the transition possibility matrix between two consecutive replenishment cycles with a set of states $\{0,1, \ldots, S\}$. Then, $\overline{\overline{M_{R}}}=\overline{\overline{M_{R-L}}} \cdot \overline{\overline{M_{L}}}$ where $\overline{\overline{M_{R-L}}}=\left[m_{i j}\right]$ and $\overline{\overline{M_{L}}}=\left[s_{j k}\right.$ represent the possibility transition matrices of the on-hand stock levels from the order delivery to the review instant, and from the review instant to the next order delivery, respectively.

Then, to calculate $\overline{\overline{M_{R-L}}}=\left[m_{i j}\right]$ we need to know the stock balance at the review instant (i.e. R-L). In a periodic review system with lost sales the on-hand stock at the review is defined as $O H_{R-L}=\left[O H_{0}-D_{R-L}\right]^{+}$. Therefore, 


$$
m_{i j}= \begin{cases}\operatorname{Pos}\left(D_{R-L} \geq i\right)=1-F_{R-L}(i-1) & j=0 \\ \operatorname{Pos}\left(D_{R-L}=i-j\right)=f_{R-L}(i-j) & j>0\end{cases}
$$

Following the same reasoning, in order to obtain $\overline{\overline{M_{L}}}=\left[s_{j k}\right]$ we need to define the stock balance at order delivery (i.e. $L$ ) in a periodic review system with lost sales, which is $O H_{R}=\left[O H_{R-L}-D_{L}\right]^{+}+S-O H_{R-L}$, thus:

$$
S_{j k}= \begin{cases}0 & k+j-S<0 \\ \operatorname{Pos}(k=S-j)=P\left(D_{L} \geq j\right)=1-F_{L}(j-1) & k+j-S=0 \\ \operatorname{PoS}\left(k=j-D_{L}+S-j=S-D_{L}\right)=P\left(D_{L}=S-k\right)=f_{L}(S-k) & k+j-S>0\end{cases}
$$

As has been previously explained, in the original method of Cardós et al. (2006), the eigenvector is obtained when probabilistic matrices converge, i.e. when they reach the stability. In crisp environments, it is proven that stability is reached when the difference between rows are zero, and this difference tends to zero as the number of iterations increases. Therefore, an efficient approach consists of stopping the iterative process when differences between rows are small enough, thus simplifying calculations and, consequently, reducing the required time. Our proposal is, precisely, the adaptation of this reasoning to fuzzy logic and estimating the eigenvector with interval-valued fuzzy sets (Bustince, Marco-Detchart, Fernández, Wagner, Garibaldi \& Takáč, 2019; Deschrijver \& Kerre, 2003). To implement this approach, we construct the Markov chain using possibility functions, so that the eigenvector of $M_{R}$ becomes fuzzy and represents the possibility vector of the on-hand stock levels, indeed.

$$
\left[\begin{array}{c}
m_{1}^{l} \\
m_{S+1}^{l}
\end{array}\right] \rightarrow\left[\begin{array}{c}
m_{1}^{2} \\
m_{S+1}^{2}
\end{array}\right] \ldots \rightarrow\left[\begin{array}{c}
m_{1}^{k} \\
m_{S+1}^{k}
\end{array}\right] \quad m_{j}^{r} \in \mathbb{R}^{S+1} \quad r=1, \ldots, k
$$

For each iteration, we calculate the difference between the highest and the smallest element of each row $\left(\varepsilon_{j}\right)$, i.e.

$$
\left|\max _{k} m_{j}^{k}-\min _{k} m_{j}^{k}\right|<\varepsilon_{j} \quad 1 \leq j \leq S+1
$$

We define the error as the largest value of $\varepsilon_{j}$, i.e. $\varepsilon=\max \left\{\varepsilon_{1}, \ldots, \varepsilon_{S+1}\right\}$ and the iterative process stops when $\varepsilon$ arrives at an established value. This value represents the maximum error that an expert would accept (i.e. a tolerance level). The final step is then the defuzzification. In this case, we propose a reduction converting it to a membership function of a fuzzy set type 1 (Runkler, Chen \& John, 2018).

\subsection{Illustrative Examples}

The goal of this section is to illustrate how the proposed fuzzy method simplifies the calculation of the on-hand stock levels by reducing the computational efforts whilst correctly calculating the on-hand stock vector. Table 1 shows the on-hand stock vector obtained for $R=4, S=5$ and $L=1,2,3$ when the tolerance level is set at $\varepsilon=10 \%$. In these examples, the fuzzy method needs only 2 or 3 iterations to achieve the established tolerance level, whereas the stochastic method needs 64 or 65 iterations to reach the convergence. However, when comparing both vectors, it can be seen that the fuzzy method obtains a very accurate calculation of each element of the vector. To quantify the deviations of the fuzzy vector, we compute the module of the error vector with the following expression:

$$
\text { Deviation }=\frac{|\vec{s}-\vec{f}|}{|\vec{f}|}
$$

where $\vec{S}$ represents the stochastic vector and $\vec{f}$ the fuzzy vector. Deviations obtained for each case are smaller than one thousandth. Concretely they are: 0.000582 for Case 1, 0.000026 for Case 2 and 0.000391 for Case 3. These 
insignificant deviations illustrate the good performance of the proposed fuzzy method with a significantly reduced number of iterations.

\begin{tabular}{|c|c|c|c|c|c|c|c|c|}
\hline Example & Method & $P\left(\mathrm{OH}_{0}\right)$ & $P\left(\mathrm{OH}_{1}\right)$ & $P\left(\mathrm{OH}_{2}\right)$ & $\mathrm{P}\left(\mathrm{OH}_{3}\right)$ & $\mathrm{P}\left(\mathrm{OH}_{4}\right)$ & $P\left(\mathrm{OH}_{5}\right)$ & Iterations \\
\hline Case 1 & Stochastic & 0.0001 & 0.0016 & 0.0170 & 0.1000 & 0.3261 & 0.5553 & 64 \\
\hline$L=1$ & Fuzzy & 0.0001 & 0.0016 & 0.0171 & 0.1001 & 0.3263 & 0.5550 & 2 \\
\hline Case 2 & Stochastic & 0.0013 & 0.0156 & 0.0802 & 0.2263 & 0.3591 & 0.3176 & 65 \\
\hline$L=2$ & Fuzzy & 0.0013 & 0.0156 & 0.0802 & 0.2263 & 0.3591 & 0.3176 & 3 \\
\hline Case 3 & Stochastic & 0.0064 & 0.0484 & 0.1645 & 0.3017 & 0.3065 & 0.1726 & 65 \\
\hline$L=3$ & Fuzzy & 0.0064 & 0.0485 & 0.1646 & 0.3017 & 0.3064 & 0.1724 & 3 \\
\hline
\end{tabular}

Table 1. Comparison of the $\overline{P\left(O H_{R}\right)}$ and the number of iterations when $\mathrm{R}=4, S=5$ and $\varepsilon=10 \%$

\section{Managerial Implications: Impact on Service Measures}

Knowing the available stock levels at order delivery is a critical piece of information for inventory managers to both determine customer service levels and establish the control parameters of the inventory policy that lead to the definition of the total costs of the system. In practice however, it is very difficult to determine total inventory costs because of the difficulty in quantifying the shortage cost, i.e. the cost incurred by a stockout (Larsen \& Thorstenson, 2008). In this sense, (Liberopoulos, Tsikis \& Delikouras, 2010) distinguishes two types of shortage cost: the direct cost, which can be easily calculated as the demand that is lost or backordered, and the indirect cost, which is actually the hard part to evaluate and is related to the loss of customer goodwill and damage to the image of the company. However, in a lost sales context even the direct cost is difficult to determine since unfulfilled demand is not only lost but also, in some cases, unrecorded. For that reason, practitioners tends to use the service approach that consists of computing control parameters of the inventory policy by means of defining a target service level (Zipkin, 2000). To implement this approach first, it is required to select which service measure will determine the policy. In this sense, the fill rate $(\beta)$ has been widely used since it considers not only the possibility that the system is out of stock, but also the size of the unfulfilled demand when it occurs (Silver, Pyke, \& Thomas, 2017; Tempelmeier, 2007). This metric is commonly defined as the fraction of demand that is immediately satisfied from the stock on the shelf and can be expressed as:

$$
\beta=1-\frac{E(\text { unfilled demand })}{E(\text { total demand })}
$$

When the inventory is periodically reviewed and the unfilled demand is lost, the expression to calculate the fill rate based on (Guijarro, Cardós \& Babiloni, 2012) is:

$$
\beta=1-\frac{\sum_{i=0}^{S} \operatorname{Pos}\left(O H_{R}=i\right) \cdot \sum_{j=i+1}^{\infty}(j-i) \cdot f_{R}(j)}{\sum_{j=1}^{\infty} j \cdot f_{R}(j)}
$$

Note that on-hand stock levels at order delivery are required to obtain the fill rate. The goal of this section is to illustrate the impact on the fill rate when it is estimated with the proposed possibility eingenvector. To achieve this objective, we design the following experiment (see Figure 2). First, we combine different input data related to the inventory policy $(R, L$ and $S$ ). These input data are selected in order to provide realistic values of the fill rate (from 0.5 to 0.99 ) and to represent both the smooth and the intermittent demand categories according to (Syntetos, Boylan \& Croston, 2005) categorization. Then, for each input data combination, we calculate, on the one hand, the fuzzy on-hand stock vector and use this vector in expression (7) to obtain the fuzzy fill rate. On the other hand, we 
simulate a $(\mathrm{R}, S)$ inventory system using Monte Carlo method, which follows the systems description of Section 2. For each input data combination, we calculate the achieved fill rate when considering 20,000 consecutive periods as:

$$
\beta_{\text {achieved }}=\frac{1}{T} \sum_{t=1}^{T} 1-\frac{\text { unfilled demand }_{t}}{\text { total demand }}
$$

where $T$ indicates the total number of replenishment cycles. To assure the consistency of the results, Monte Carlo simulations accomplish 30 replications of each case using the average of these replications as the final achieved fill rate.

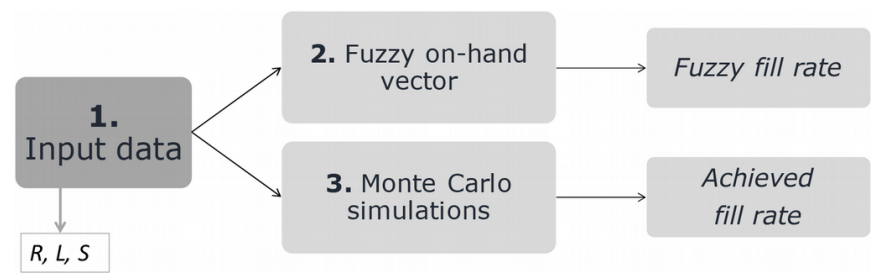

Figure 2. Experimental design

Table 2 presents the considered experimental set of data (excluding cases where $\mathrm{R}<\mathrm{L}$ ). The total number of experiments is 162 . We focus on fill rates greater than $50 \%$, filtering the number of experiments to 152 .

\begin{tabular}{|l|l|}
\hline $\boldsymbol{R}$ & $4,5,6$ \\
\hline $\boldsymbol{L}$ & $1,2,3$ \\
\hline $\boldsymbol{S}$ & $5,7,9$ \\
\hline
\end{tabular}

Table 2. Parameters of the experiment

Figure 3 compares the fuzzy fill rate and the achieved fill rate plotted as black circles and as a solid line respectively, when the tolerance level is set as $\varepsilon=10 \%$. As can be seen, the proposed fuzzy method properly estimates the fill rate in all the cases, even when the fill rate level is lower than $90 \%$. Normally, approximations in the literature present good performance when the fill rate is high (see Cardós et al., 2017). This behaviour is logical due to the fact that, with high levels of fill rate, the system satisfies almost all the demand so the number of stockouts are low. However, we can observe that, even for cases where the fill rate is lower than $80 \%$, our proposed method leads to a very accurate fill rate estimation. In fact, the average and standard deviation of errors are $0.015 \%$ and $0.041 \%$ respectively, which illustrates the accuracy of the fuzzy on-hand vector when used for fill rate estimation.

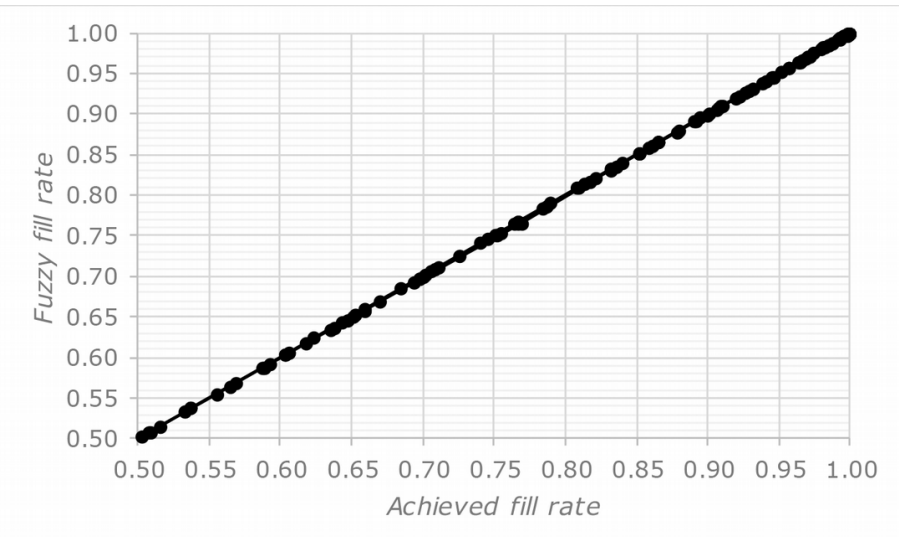

Figure 3. Fuzzy versus achieved fill rate scatter plots 
As the introduction points out, in practical environments the fill rate is used to establish control parameters of the inventory policy, or in other words, to compute the minimum base-stock level, $S$, that guarantees a target fill rate. The difficulty of computing the fill rate in a $(R, S)$ system with lost sales is in the calculation of the on-hand stock vector (see expression (8)). In the literature, we find different approaches to obtain the on-hand vector for a $(R, S)$ policy and lost sales. However, these approaches may incur some risks when they are used to determine the base-stock levels. As is detailed explained by (Cardós et al., 2017), some of them can lead to an increase of the stock level and, consequently, of holding costs, whereas other approaches can underestimate the base-stock level which implies that the target fill rate is not achieved and the system is actually less protected against stockout occasions than might be expected.

However, the fuzzy vector suggested in this work obtains a very accurate calculation of each element of the vector with almost zero deviations from the exact one while significantly reducing mathematical complexity and computational costs. In this sense, from a practical perspective, the smaller the difference in the vector is, the lower its impact on service levels (as can be seen Figure 3) and consequently the impact on the determination of control parameters of the inventory policy when using the fuzzy approach is negligible.

\section{Conclusions}

This paper presents a new fuzzy application in inventory management. More concretely, we propose a new fuzzy method to calculate the on-hand stock level at order delivery in a periodic review system where unfilled demand is lost. Inventory managers need to know the available stock levels to satisfy new demands, i.e. what is the on-hand stock level at order delivery to satisfy the demand that arrives to the system. This information is required to calculate inventory costs and to analyze the performance of the inventory policy in terms of service measures. However, the calculation of the on-hand stock level at the beginning of the cycle in lost sales models is quite complex, mainly because it cannot be computed as the difference between the base-stock and the accumulated demand during the lead time.

In the literature, we find a stochastic expression proposed by Cardós et al. (2006) to obtain the exact on-hand stock level vector. However, this method is not a closed-form expression and requires huge computational efforts mainly for large $S$ values, which hinder its implementation in practical environments or information systems. This paper proposes a new fuzzy method specifically derived by considering the characteristics of lost sales systems. The proposed expression obtains a very accurate estimation of the on-hand vector with deviations of 0.00015 on average, whilst significantly reducing computational costs, which makes this method easily implementable in practical environments. Moreover, when it is used to calculate service measures, specifically the fill rate, the fuzzy method shows good performance even for values of fill rate lower than $80 \%$ when the number of stockouts increases. In practical environments, the fill rate is used to determine the parameters of the system. In the lost sales context, however, its calculation is quite complex due to the need to know the on-hand stock vector. The proposed fuzzy method, which reduces the mathematical complexity, properly calculates the fill rate, which allows an accurate determination of control parameters. Therefore, we propose a close-form method which enhances its applicability in practical environments since, from a practical perspective, "an understandable decision rule that improves somewhat on current conditions is almost certainly better than the optimal solution that is neither understood nor accepted by management" (Silver, 2008).

Further research should focus on applying the same reasoning in other inventory policies such as the continuous review policy.

\section{Declaration of Conflicting Interests}

The authors declared no potential conflicts of interest with respect to the research, authorship, and/or publication of this article.

\section{Funding}

This work was supported by Generalitat Valenciana under the project with reference GV/2017/032. 


\section{References}

Babiloni, E., Cardós, M., \& Guijarro Tarradellas, E. (2011). On the exact calculation of the mean stock level in the base stock periodic review policy. Journal of Industrial Engineering and Management, 4, 194-205.

https://doi.org/10.3926/jiem.2011.v4n2.p194-205

Bijvank, M., \& Vis, I.F.A. (2011). Lost-sales inventory theory: A review. European Journal of Operational Research, 215(1), 1-13. https://doi.org/10.1016/j.ejor.2011.02.004

Bijvank, M., Huh, W.T., Janakiraman, G., \& Kang, W. (2014). Robustness of order-up-to policies in lost-sales inventory systems. Operations Research, 62(5), 1040-1047. https://doi.org/10.1287/opre.2014.1298

Bijvank, M., \& Johansen, S.G. (2012). Periodic review lost-sales inventory models with compound Poisson demand and constant lead times of any length. European Journal of Operational Research, 220(1), 106-114.

https://doi.org/10.1016/j.ejor.2012.01.041

Breugelmans, E., Campo, K., \& Gijsbrechts, E. (2006). Opportunities for active stock-out management in online stores: The impact of the stock-out policy on online stock-out reactions. Journal of Retailing, 82(3), 215-228. https://doi.org/10.1016/j.jretai.2006.05.001

Bustince, H., Marco-Detchart, C., Fernández, J., Wagner, C., Garibaldi, J.M., \& Takáč, Z. (2019). Similarity between interval-valued fuzzy sets taking into account the width of the intervals and admissible orders. Furay Sets and Systems. https://doi.org/10.1016/j.fss.2019.04.002

Cardós, M., \& Babiloni, E. (2011a). Exact and approximate calculation of the cycle service level in periodic review inventory policies. International Journal of Production Economics, 131(1), 63-68. https://doi.org/10.1016/j.ijpe.2010.05.012

Cardós, M., \& Babiloni, E. (2011b). Exact and approximated calculation of the cycle service level in a continuous review policy. International Journal of Production Economics, 133(1), 251-255. https://doi.org/10.1016/j.ijpe.2010.09.017

Cardós, M., Guijarro, E., \& Babiloni, E. (2017). On the estimation of on-hand stocks for base-stock policies and lost sales systems and its impact on service measures. International Journal of Production Research, 55(16), $4680-4694$. https://doi.org/10.1080/00207543.2017.1279759

Chikán, A. (2007). The new role of inventories in business: Real world changes and research consequences. International Journal of Production Economics, 108(1-2), 54-62. https://doi.org/10.1016/j.ijpe.2006.12.002

Chikán, A. (2011). Managers' view of a new inventory paradigm. International Journal of Production Economics, 133(1), 54-59. https://doi.org/10.1016/j.ijpe.2010.09.009

Cardós, M., Miralles, C., \& Ros, L. (2006). An exact calculation of the cycle service level in a generalized periodic review system. Journal of the Operational Research Society, 57, 1252-1255. https://doi.org/10.1057/palgrave.jors.2602121

Deschrijver, G., \& Kerre, E.E. (2003). On the relationship between some extensions of fuzzy set theory. Fuzzy Sets and Systems, 133(2), 227-235. https://doi.org/10.1016/S0165-0114(02)00127-6

Dey, O., \& Chakraborty, D. (2012). A fuzzy random periodic review system with variable lead-time and negative exponential crashing cost. Applied Mathematical Modelling, 36(12), 6312-6322. https://doi.org/10.1016/j.apm.2011.09.047

Dey, O., \& Chakraborty, D. (2011). A fuzzy random continuous review inventory system. International Journal of Production Economics, 132(1), 101-106. https://doi.org/10.1016/j.ijpe.2011.03.015

Diels, J.L., \& Wiebach, N. (2011). Customer reactions in Out-of-Stock situations: Do promotion-induced phantom positions alleviate the similarity substitution bypothsis? Working Paper No. 2011-021. Available at: https://www.econstor.eu/handle/10419/56677

Dutta, P., Chakraborty, D., \& Roy, A.R. (2007). An inventory model for single-period products with reordering opportunities under fuzzy demand. Computers and Mathematics with Applications, 53(10), 1502-1517.

https://doi.org/10.1016/j.camwa.2006.04.029 
Garai, T., \& Garg, H. (2019). Multi-objective linear fractional inventory model with possibility and necessity constraints under generalised intuitionistic fuzzy set environment. CAAI Transactions on Intelligence Technology, 4(3), 175-181. https://doi.org/10.1049/trit.2019.0030

Garg, H. (2015). Fuzzy inventory models for deteriorating items under different types of lead-time distributions. In Intelligent Techniques in Engineering Management (247-274). Cham: Springer. https://doi.org/10.1007/978-3-319-179063_11

Gruen, T.W., Corsten, D., \& Bharadwaj, S. (2002). Retail Out-of-Stocks: A Worldwide Examination of Extent Causes, Rates and Consumer Responses. Washington, D.C.: Grocery Manufacturers of America.

Guiffrida, A.L., \& Nagi, R. (1998). Fuzzy set theory applications in production management research: A literature survey. Journal of Intelligent Manufacturing, 9(1), 39-56. https://doi.org/10.1023/A:1008847308326

Guijarro, E., Cardós, M., \& Babiloni, E. (2012). On the exact calculation of the fill rate in a periodic review inventory policy under discrete demand patterns. European Journal of Operational Research, 218(2), 442-447. https://doi.org/10.1016/j.ejor.2011.11.025

Johansen, S.G. (2013). Modified base-stock policies for continuous-review, lost-sales inventory models with Poisson demand and a fixed lead time. International Journal of Production Economics, 143(2), 379-384.

https://doi.org/10.1016/j.ijpe.2012.02.021

Kahraman, C., Gülbay, M., \& Kabak, Ö. (2006). Applications of Fuzzy Sets in Industrial Engineering: A Topical Classification. In Kahraman, C. (Ed.), Fuzzy Applications in Industrial Engineering (1-55). https://doi.org/10.1007/3540-33517-X_1

Katagiri, H., \& Ishii, H. (2002). Fuzzy inventory problems for perishable commodities. European Journal of Operational Research, 138(3), 545-553. https://doi.org/10.1016/S0377-2217(01)00074-1

Ko, M., Tiwari, A., \& Mehnen, J. (2010). A review of soft computing applications in supply chain management. Applied Soft Computing, 10(3), 661-674. https://doi.org/10.1016/j.asoc.2009.09.004

Kouki, C., Babai, M.Z., Jemai, Z., \& Minner, S. (2018). Solution procedures for lost sales base-stock inventory systems with compound Poisson demand. International Journal of Production Economics, 209, 172-182. https://doi.org/10.1016/j.ijpe.2018.01.021

Larsen, C., \& Thorstenson, A. (2008). A comparison between the order and the volume fill rate for a base-stock inventory control system under a compound renewal demand process. Journal of the Operational Research Society, 59(6), 798-804. https://doi.org/10.1057/palgrave.jors.2602407

Liberopoulos, G., Tsikis, I., \& Delikouras, S. (2010). Backorder penalty cost coefficient "b”: What could it be? International Journal of Production Economics, 123(1), 166-178. https://doi.org/10.1016/j.ijpe.2009.07.015

Mula, J., Poler, R., García-Sabater, J.P., \& Lario, F.C. (2006). Models for production planning under uncertainty: A review. International Journal of Production Economics, 103(1), 271-285. https://doi.org/10.1016/j.ijpe.2005.09.001

Pai, P.F., \& Hsu, M.M. (2003). Continuous review reorder point problems in a fuzzy environment. The International Journal of Advanced Manufacturing Technology, 22(5), 436-440. https://doi.org/10.1007/s00170-003-1559-4

Runkler, T.A., Chen, C., \& John, R. (2018). Type reduction operators for interval type-2 defuzzification. Information Sciences, 467, 464-476. https://doi.org/10.1016/j.ins.2018.08.023

Sarkar, B., \& Mahapatra, A.S. (2015). Periodic review fuzzy inventory model with variable lead time and fuzzy demand. International Transactions in Operational Research, 1-31. Retrieved from Scopus.

Shekarian, E., Kazemi, N., Abdul-Rashid, S.H., \& Olugu, E.U. (2017). Fuzzy inventory models: A comprehensive review. Applied Soft Computing, 55, 588-621. https://doi.org/10.1016/j.asoc.2017.01.013 
Silver, E.A. (2008). Inventory Management: An Overview, Canadian Publications, Practical Applications and Suggestions for Future Research. INFOR: Information Systems and Operational Research, 46(1), 15-27. https://doi.org/10.3138/infor.46.1.15

Silver, E.A., Pyke, D.F., \& Thomas, D.J. (2017). Inventory and Production Management in Supply Chains. https://doi.org/10.1201/9781315374406

Syntetos, A.A., Boylan, J.E., \& Croston, J.D. (2005). On the categorization of demand patterns. Journal of the operational research society, 56(5), 495-503. https://doi.org/10.1057/palgrave.jors.2601841

Taleizadeh, A.A., Niaki, S.T.A., \& Aryanezhad, M.B. (2010). Optimising multi-product multi-chance-constraint inventory control system with stochastic period lengths and total discount under fuzzy purchasing price and holding costs. International Journal of Systems Science, 41(10), 1187-1200. https:/ / doi.org/10.1080/00207720903171761

Tempelmeier, H. (2007). On the stochastic uncapacitated dynamic single-item lotsizing problem with service level constraints. European Journal of Operational Research, 181(1), 184-194. https://doi.org/10.1016/j.ejor.2006.06.009

Zadeh, L.A. (1965). Fuzzy sets. Information and Control, 8(3), 338-353. https://doi.org/10.1016/S0019-9958(65)90241-X

Zipkin, P.H. (2000). Foundations of Inventory Management. McGraw-Hill Higher Education.

Journal of Industrial Engineering and Management, 2020 (www.jiem.org)

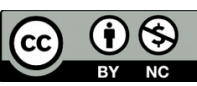

Article's contents are provided on an Attribution-Non Commercial 4.0 Creative commons International License. Readers are allowed to copy, distribute and communicate article's contents, provided the author's and Journal of Industrial Engineering and Management's names are included. It must not be used for commercial purposes. To see the complete license contents, please visit https://creativecommons.org/licenses/by-nc/4.0/. 